\title{
自支撑 $\mathrm{WS}_{2} /$ 碳纤维复合材料的静电纺丝制备及其 作为锂离子电池负极材料的应用
}

周沙沙 ${ }^{\mathbb{1}}$, 陈俊年 ${ }^{\mathbb{1}}$, 甘霖 ${ }^{\mathbb{1}}$ ，章庆 ${ }^{\mathbb{1}}$ ，郑志 ${ }^{\mathbb{1}}$ ，李会巧 ${ }^{(12 * *}$, 翟天佑 $\mathbb{1}^{*}$

(1) 华中科技大学材料科学与工程学院, 材料成形与模具技术国家重点实验室, 武汉 430074;

(2) 南开大学先进能源材料化学教育部重点实验室, 天津 300071

* 联系人, E-mail: hqli@ hust.edu.cn; zhaity@ hust.edu.cn

国家重点基础研究发展计划(2015CB932600)、国家自然科学基金(21571073，51302099)、教育部新世纪优秀人才计划(NCET-13-0227)、华 中科技大学创新交叉重点创新团队项目和中央高校基础研究基金资助

过渡金属硫族化合物(TMDs) $\mathrm{MX}_{2}$ $(\mathrm{M}=\mathrm{W}, \mathrm{Mo}, \mathrm{V} ; \mathrm{X}=\mathrm{S}, \mathrm{Se}, \mathrm{Te})$ 作为一种典 型的类石墨二元层状化合物, 近年来被 广泛用作锂离子电池负极材料. 与石墨 相比, $\mathrm{MX}_{2}$ 具有更大的层间距, 更有利 于锂离子的快速嵌人和脱出, 同时具有 更大的理论比容量, 是一种很有潜力的 锂电负极材料. 本课题组利用静电纺丝 技术一步法制得了 $\mathrm{WS}_{2}$ 单层或少层纳米 片均匀镶嵌在碳纳米纤维的一种自支撑 复合材料, 并研究了 $\mathrm{WS}_{2}$ 结晶程度对其 电化学性能的影响. 该制备方法操作简 单、产量高、可控性强, 而且所得的 $\mathrm{WS}_{2} /$ 碳纤维薄膜具有良好的柔韧性, 可以直 接作为自支撑电极使用, 表现出良好的 电化学综合性能.

$\mathrm{MX}_{2}$ 导电性较差, 在嵌锂脱锂过程 中伴随有较大的体积变化, 严重影响了 电池的循环和倍率性能. 为了提高 $\mathrm{MX}_{2}$ 的电化学性能, 需要降低其颗粒尺寸, 构造少层或单层的 $\mathrm{MX}_{2}$. 纳米片层的 $\mathrm{MX}_{2}$, 不仅能够缓解材料在嵌、脱锂过 程中的体积变化, 还使材料获得了巨大 的比表面积, 为锂离子提供更多的界面 储存位点. 目前制备少层或单层 $\mathrm{MX}_{2}$ 的 方案多是基于溶液法, 其过程相对复 杂、产量低, 且在后续的收集过程中, 片 层 $\mathrm{MX}_{2}$ 容易重聚, 限制了其应用. 另一
方面, 为了改善材料的导电性, 可将制 得的 $\mathrm{MX}_{2}$ 与导电性良好的石墨烯、碳纳 米管等进行复合, 用以提高其电化学性 能; 然而, 这种事后复合的方法很难实 现 $\mathrm{MX}_{2}$ 与导电材料在纳米尺度上的均匀 复合. 相比之下, 静电纺丝作为一种简 单、普适且可大量制备一维纳米材料的 方法, 可以同时满足以上两点. 纺丝纤 维中的高分子会在后续的热处理中发生 碳化, 因此可以原位得到具有良好导电 性的碳纤维. 碳纤维的存在不仅可以增 加导电性, 还可以限制 $\mathrm{MX}_{2}$ 颗粒的生长, 阻止 $\mathrm{MX}_{2}$ 纳米片的聚集堆叠, 一步实现 $\mathrm{MX}_{2}$ 的单片化和导电性改善的目的. 本课题组利用静 电纺丝技术, 成功制备 出二维 $\mathrm{WS}_{2}$ 纳米片均匀 镶嵌在碳纳米纤维的 复合材料(图 1). 这种 均匀分散的单层或少 层 $\mathrm{WS}_{2}$ 纳米片具有极大 的比表面积和极小的 尺寸, 可以提供较多的 界面储锂和快速的离 子和电子传输通道, 因 此表现出优异的锂电 性能. 在 $100 \mathrm{~mA} / \mathrm{g}$ 的电 流密度下, 其首次充放
电比容量高达756/941 mAh/g. 通过改变 热处理温度, 可以得到不同结晶程度的 $\mathrm{WS}_{2}$; 电化学测试结果表明, $\mathrm{WS}_{2}$ 的结晶 度升高, 容量会下降, 可能是由于低结晶 性的 $\mathrm{WS}_{2}$ 拥有更大的比表面积, 可以为 锂离子提供更多的界面储存位点.

此外, 该静电纺丝技术制备的 $\mathrm{WS}_{2} /$ 碳纤维复合材料是一种自支撑的薄 膜. 该薄膜具有良好的柔韧性和弯曲性, 可以直接用作锂电负极, 不需要额外添 加导电剂和黏结剂; 同时表现出良好的 电化学性能. 这种简单的制备自支撑电 极材料的方法为柔性电池器件的发展提 供了一种契机.

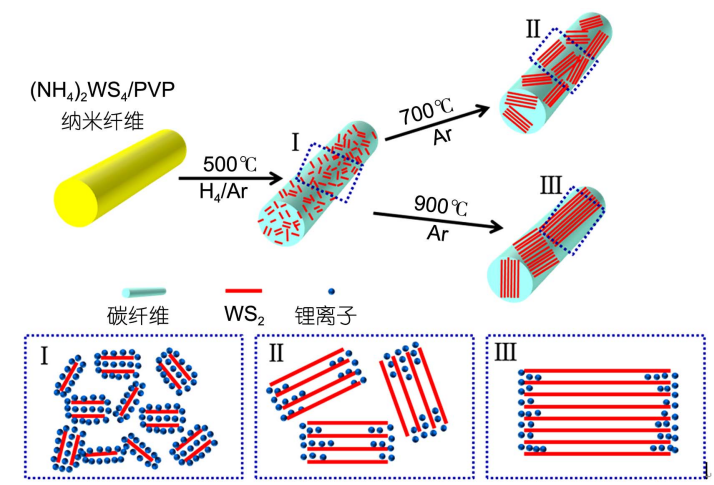

图 1 (网络版彩色)静电纺丝纤维经不同热处理条件转变为不同 结晶度的 $\mathrm{WS}_{2}$ /碳纤维的过程示意图. 热处理的温度越高, $\mathrm{WS}_{2}$ 的 结晶度越高, 储存锂离子的数目越少, 对应的电化学性能越差

全文见: Zhou S S, Chen J N, Gan L, et al. Scalable production of self-supported $\mathrm{WS}_{2} / \mathrm{CNFs}$ by electrospinning as the anode for high-performance lithium-ion batteries. Sci Bull, 2016, 61: 227-235, doi: 10.1007/s11434-015-0992-8 